\title{
Escritos médico-psicopedagógicos sobre a criança: os projetos de caderneta individual no século XX
}

Samuel Boussion

\section{Resumo}

Este artigo discorre sobre os projetos de cadernetas médico-pedagógicas individuais para as crianças e sobre a sua evolução. Ao longo do século XX, podem-se identificar múltiplas tentativas de instituir-se uma caderneta que, seguindo o modelo da caderneta de saúde, também levaria em conta os dados psicológicos e pedagógicos. Elas se situam inicialmente numa perspectiva de higiene escolar, mas se espraiam também para o campo da profilaxia, com o objetivo de identificar as crianças "anormais", e, um pouco mais tarde, para o campo da orientação profissional. A Segunda Guerra Mundial produz também uma abordagem diferente, em termos de racionalização dos escritos médicos e psicológicos sobre a criança, buscando considerar os eventos sociais e o que eles possam ter gerado na criança, sem, no entanto, distanciar-se das antigas categorias ligadas ao biológico. Muito provavelmente as novidades encontram-se antes no fato de que se pretende confiar às crianças a caderneta médico-pedagógica, mas esses parênteses serão logo cerrados e finalmente se apagam ante as críticas do que se considera como uma forma de controle social.

Palavras-chave: História. Médico-pedagógico. Ppsicologia. Psiquiatria da criança. Caderneta de saúde.

\section{Introdução}

Num momento em que nos questionamos sobre as consequências psicológicas de várias semanas de isolamento social, e que se elaboram meios para a testagem e o monitoramento, é consenso que a saúde das crianças

I Doutor em Historia. CIRCEFT axe HEDUC, Universidade Paris 8 Saint-Denis.

\section{(c))Er}

Direito autoral e licença de uso: Este artigo está licenciado sob uma Licença Creative Commons. Com essa licença você pode compartilhar, adaptar, para qualquer fim, desde que atribua a autoria da obra, forneça um link para a licença, e indicar se foram feitas alterações. 
não pode ser entendida apenas no plano somático, mas também no psíquico. Nisso não há muita novidade. O que há de novo na verdade são os projetos de inscriçáo desse dado nos documentos de saúde das crianças. $\mathrm{Na}$ França, pouco antes da crise na saúde pública, um relatório já previa acrescentar à caderneta de saúde mantida pelas famílias e pelo seu médico a noção de "saúde cultural". A psicanalista Sophie Marinopoulos justifica-a como "a saúde das nossas relações"; nesse sentido, lamenta que a caderneta de saúde atual, e mais amplamente os discursos e práticas médicas, tenderiam a reduzir a saúde da criança às suas características fisiológicas, negligenciando a dimensão global do seu desenvolvimento, particularmente o despertar artístico e cultural cuja carência comprometeria a psique ${ }^{3}$. Essa atenção sobre o acompanhamento da saúde psíquica das crianças náo é inédita na pena dessa especialista, já que ela publicara Mon carnet de santé psy, obra dirigida aos pais que, seguindo o modelo da caderneta de saúde, tem como objetivo monitorar a saúde psíquica da criança (MARINOPOULOS, 2012).

Essas preocupações tanto com a saúde quanto com o registro escrito, tấo da nossa época, apostando no desenvolvimento pluridimensional da criança e no investimento das famílias, parecem, não obstante, e olhando bem de perto, inscrever-se numa história da medicalização e da psicologização da infância. Há, de fato, toda uma historicidade das práticas de escrita sobre a saúde das crianças que, ao longo de todo o século XX, buscaram registrar fielmente não somente os ensinamentos médicos mas também os perfis psicológicos e, por vezes, buscaram confiar esses documentos às famílias ou aos próprios menores, a partir do princípio da caderneta de saúde das crianças. Isso nos veio à luz ao cabo de uma pesquisa sobre uma organização internacional dedicada à causa das crianças, realizada na Suíça no final do ano de 1994, denominada "Semanas Internacionais de Estudo para a Infância Vítima da Guerra”, cujo nome é amiúde reduzido ao seu acrônimo: SE`PEG (BOUSSION, 2013). Dos seus arquivos, dentre atas, relatórios e correspondência, emergiu um objeto singular: a

2 Émancipation par la culture, relatório entregue ao primeiro-ministro em 17 de fevereiro de 2020 por Aurore Bergé.

3 "Hoje em dia, a falta de despertar cultural e artístico nas nossas crianças é um flagelo da saúde pública", entrevista com Sophie Marinopoulos, por: Vergely, J. Télérama, 23 jun. 2019. 
"caderneta médico-pedagógica"4. Trata-se de uma pequena caderneta de capa sóbria, cinza azulada, contando uma dezena de páginas e medindo aproximadamente $12 \mathrm{~cm}$ de altura por no máximo $10 \mathrm{~cm}$ de largura. $\mathrm{O}$ documento é um protótipo, virgem de escrita, mas no qual todas as rubricas foram impressas. A caderneta médico-pedagógica é dirigida ao pessoal encarregado das chamadas crianças "vítimas de guerra", que se encontram na maioria das vezes em campos de refugiados, centros de acolhimento ou outras instituiçóes criadas para essa finalidade. Como essas crianças se veem frequentemente obrigadas a mudar de local de alojamento, a caderneta foi concebida para que a criança a leve consigo, para que ela possa ser preenchida e lida por outros profissionais, traçando assim o seu perfil individual e o seu desenvolvimento. Ela consiste numa redução em registro escrito da saúde física, psíquica e dos efeitos educativos da tutela das crianças, a partir de diferentes itens: estado civil e identificação, histórico familiar, perfil intelectual e perfil médico, nos planos somático e psíquico, além de anotaçóes pedagógicas.

Essa caderneta que entra no atendimento clínico da criança vítima de guerra, se distingue pela multiplicidade de pontos de vista sobre a criança. Mas, ainda sobre esse assunto, sem querer a todo custo voltar no tempo, ela parece da mesma maneira enraizar-se numa história do tratamento clínico da criança-problema, uma visão que se torna cada vez mais forte ao menos desde o final do século XIX. Tenha sido ela capturada nas malhas da justiça, rotulada como "moralmente abandonada" pelas deficiências do seu meio familiar e social, ou avaliada como "deficiente", "anormal" ou, ainda, um pouco mais adiante, "especial", desencadeia-se, de fato, todo um processo de individualização progressiva dos diagnósticos e das medidas. No cerne desse dispositivo, um dos traços mais visíveis e materiais dessa atenção singular é o dossiê individual montado dentro dessas instituiçóes, sejam elas órgãos de justiça, de assistência social à criança ou médico-pedagógicas, mas também em cada segmento administrativo ou judiciário que seja responsável, tribunal ou órgão de assistência social (BOUSSION; GARDET, 2010). Esses dossiês não vão cessar de avolumar-se ao longo do século XX, com variaçóes segundo as instituiçóes, pois os olhares pro-

4 Archives cantonales vaudoises (Acv), fonds Oscar Forel, p. 1035-1062. 
fissionais sobre a criança multiplicam-se no decorrer do desenvolvimento de um aparelho científico cada vez mais afinado, o médico-pedagógico em particular. Mas a característica do dossiê, pelo menos até pouco tempo atrás, é de estar vinculado a cada instituiçáo; portanto, náo é esperado que esteja em posse da criança ou do adolescente. Na maior parte do tempo, oculta ao olhar da criança, a qual é afastada tanto de sua própria história, como de sua família.

Dessa forma, a caderneta médico-pedagógica dos Sepeg, como todas as outras tentativas, parece inscrever-se na encruzilhada das várias histórias da medicalização e da psicologização da infância; situa-se particularmente numa história da profilaxia, que se deve ler à luz da história mais geral da caderneta de saúde, a grande questão da promoção da higiene e da saúde desde o início do século XX, quando os médicos se debruçaram sobre ela (ROLLET, 2007). Também nesse caso trata-se de registrar informaçóes médicas sobre uma criança, mantendo um histórico do seu desenvolvimento disponível para outros profissionais. Todavia, a caderneta médico- pedagógica diferencia-se daquela, pois esta náo retrata a criança desde o seu nascimento, mas no momento presente; por essa razáo, aproxima-se tanto de diferentes iniciativas surgidas ao mesmo tempo no campo da higiene escolar, no da orientação profissional e no da psicologia da criança. Essas iniciativas ilustram a importância cada vez maior dos médicos no que concerne à criança e à psicologia ao longo do último século, assim como a de um olhar especialista que visa a identificar, mas também categorizar, as crianças em função das suas capacidades e da sua saúde psíquica.

A caderneta dos SEPEG será um "fogo de palha”, já que provavelmente não foi utilizada pelas organizaçôes e profissionais aos quais ela podia dirigir-se, da mesma maneira que as outras tentativas da primeira metade do século XX permaneceram igualmente isoladas. Então, por que se interessar por um empreendimento que não foi além da fase de protótipo? Não se trata aqui de embrenhar-se na escrita de um futuro não advindo, mas antes de procurar compreender por que e de que maneira médicos, psicólogos e pedagogos puderam por tanto tempo refletir sobre tal objeto e, de algum modo, propor um devir concreto às suas conferências e reuniōes, mobilizar toda a sua energia para pensar o seu papel em relaçáo à infân- 
cia. Nos arquivos por vezes verborrágicos dos especialistas, há todo um trabalho de desconstrução que pode operar-se e, como chama a atenção a historiadora Amandine Lauro, a propósito de outros domínios: "tão áridas que possam parecer certas discussóes, há em todos os casos [...] o prazer de embrenhar-se em exercícios de imaginação dos atores da época, no que as suas elucubraçóes revelam de suas visóes do que o projeto deveria ser e, ao mesmo tempo, da constatação dos seus limites" (LAURO, 2017, [s. p.]). ${ }^{5}$

De maneira mais geral, esta é a ocasião de refletir sobre essa tentação no fim das contas bastante frequente de captar o perfil médico-psicológico ou médico-pedagógico das crianças ao longo de todo o século XX. Ela remontaria, pelo menos na França, à época do início da psicologia da infância, com o objetivo de seguir o desenvolvimento dos comportamentos infantis no momento da escolarização, mas também com o objetivo de identificar as crianças “anormais". De fato, a caderneta médico-pedagógica parece encontrar um terreno de aplicação com a figura da criança vítima de guerra, no cerne de uma atenção renovada de especialistas vindos de diferentes especialidades (psiquiatria, psicologia, educação, assistência social), como sugere o projeto dos Sepeg, ao mesmo tempo que se evidencia uma crescente circulação internacional. Enfim, o pós-Segunda Guerra Mundial marca simultaneamente a continuação de outras orientaçóes, por exemplo, em torno da psicologia escolar - todavia, sem sucesso -, indo de encontro às primeiras contestaçóes do que é considerado como uma forma de controle social, a inícios dos anos 1980.

\section{A caderneta médico-pedagógica: ferramenta de higiene escolar}

Examinando de perto, o modelo da caderneta médico-pedagógica imaginado no pós-guerra inscreve-se numa história mais longa dos escritos médicos sobre a criança, que não se limita ao contexto excepcional de experiência de guerra. Com efeito, desde o final do século XIX, o registro escrito sobre a infância é bastante regular (ROLLET, 2005, p. 137). Por exemplo, às crianças que começaram a trabalhar precocemente foi entregue um "livre-

5 Em "Écrire l'histoire des futurs dans le passé. Retour sur une conférence de Patrick Boucheron à l'Ulb". 
te” específico desde a metade do século, antes que essas disposições fossem especificadas e as exigências reforçadas; desde 1892, os prefeitos são assim obrigados a entregar gratuitamente às famílias, tutor ou patrão um livrete no qual deve constar estado civil e domicílio, mas também, para as crianças de 12 a 13 anos, uma justificativa de obtenção do certificado de estudos primários e um certificado de aptidão física assinado por um médico. Esse tipo de escrita encontra-se também na virada do século XX com as primeiras iniciativas de cadernetas de saúde na França, quer levam o nome de "livrete da família", "livrete da criança", "livrete da saúde da criança" etc.. Elas referem-se à profilaxia enquanto almejam fazer as famílias adotarem métodos de cuidados de saúde e suscitar uma nova atençáo no momento da luta contra a mortalidade infantil, então muito importante.

As primeiras décadas da $3^{\text {a }}$ República caracterizam-se igualmente por uma "revolução identitária" (NOIRIEL, 1991, p. 156), que se encontra no cuidado tomado na instauração dos primeiros documentos de porte obrigatório de identidade e de processos de fichamento policial, na esteira dos trabalhos de Bertillon. Entretanto, pode-se também ver nesse trabalho antropométrico uma nova forma de individualização do domínio do Estado (ABOUT, 2004, p. 28), observável, por exemplo, através da implementação em 1912 de uma caderneta para os nômades, que começa a ser imposta inclusive às crianças. Esse momento de cruzamento da antropometria com uma nova objetivação da infância, é também o momento onde se constituem dentro das varas da infância escritos médico-psicológicos individuais, considerando-se esclarecidas as decisóes do magistrado, que abrem caminho a toda uma clínica médico-social da infância (NIGET, 2011). Com efeito, a lei de 1912 que institui em França os tribunais (as varas) de crianças e adolescentes prevê ao magistrado a possibilidade de recorrer a um exame médico e médico-psicológico dos menores acusados.

Mas provavelmente será no seio da escola, no período da progressão da escolarização, onde melhor se concretiza o acompanhamento das crianças no plano médico, com a perspectiva de colocar em prática as cadernetas de saúde escolares. Desde o final do século XIX, fichas médicas individuais vêm à luz com o objetivo de monitorar o estado de saúde das crianças: altura, peso, visão, audição, exame dos órgãos e testagem de qual- 
quer doença crônica ou aguda. Esse dispositivo apoia-se na figura cada vez mais presente do médico-inspetor das escolas, cujas atribuiçôes passam progressivamente da saúde dos alunos para as questôes de prevenção e de higiene escolar (GARDET, 2010). Esses médicos, cuja presença uma circular de 14 de novembro de 1879 torna obrigatória em todas as escolas, são então encarregados da higiene escolar, desde a higiene dos locais até a higiene do aluno, tanto física quanto moral. Incumbido do monitoramento profilático, eles se encontram cada vez mais envolvidos no acompanhamento fisiológico de cada aluno, e suas atribuiçóes passam bastante rapidamente a ter uma extensão importante, já que, ao menos em Paris, além das visitas e da elaboração da ficha médica, o médico está encarregado do monitoramento do comportamento dos alunos, instado a examinar "todas as crianças suspeitas ou mal asseadas" tais quais aquelas "que se ausentaram da escola sem motivo declarado por mais de três dias" (DUFESTEL, 1911 apud GARDET, 2010, p. 16).

Nesse período, enquanto a preocupação demográfica está no seu ápice e a escola aparece como uma ferramenta de regeneração do corpo social, a higiene escolar entra na sua segunda fase de desenvolvimento (TSCHIRHART, 2008, p. 212-213). Esta adquire uma instância de difusão e institui o seu próprio congresso, destinado a ter peso no debate político. Em novembro de 1903 acontece em Paris o primeiro congresso de higiene escolar e de pedagogia fisiológica, organizado pela Liga dos Médicos e dos Pais de Família e conduzido pelo Dr. Albert Mathieu, especialista das doenças do aparelho digestório no Hospital Saint-Antoine, mas também versado nas questóes de higiene da escola e do ensino, que ele considera fundamentais para fortificar a "raça francesa" (ROUX, 1917, p. 418). Desde esse evento inaugural, a questão de uma "caderneta individual de saúde" está na ordem do dia. Tal caderneta seguiria o aluno durante todas as suas aulas e serviria para registrar o seu desenvolvimento de um ponto de vista fisiológico, mas também os "acidentes patológicos sofridos no curso dos seus estudos" (LETULLE, 1904, p. 219-220). O modelo de caderneta dos alunos continua a ser discutido, por exemplo, em 1905, na ocasião do segundo congresso nacional, onde se constatou que um único estabelecimento, o liceu Henri IV em Paris, o teria instituído, o que incita os congressistas a emitir o voto oficial de que o ministro da Instruçáo 
Pública o torne obrigatório (DINET, 1904, p. 275). A questão é levada para os congressos internacionais, já no primeiro realizado em Nuremberg em 1904, logo retomado no segundo, realizado em Londres em 1907 e também ainda no congresso de Paris de 1910, onde circulam os modelos de um pais a outro, por exemplo, os modelos de Bélgica ou de Suíça, são discutidos numa sessão sobre o "banheiro das escolas" (CONGRĖS INTERNATIONAL D’HYGIÈNE SCOLAIRE, 1910), para sensibilizar o poder político francês sobre a necessidade de legislar sobre esse ponto.

No começo do século, essa caderneta de saúde escolar é ainda uma ficção na maioria das escolas, e são raros os exemplos da sua aplicação. Há numerosos obstáculos, dos temores diante da ruptura do segredo profissional à reticência das mães que são regularmente convocadas. Nas revistas filantrópicas, médicas e psicológicas, algumas iniciativas são difundidas, por exemplo, no Colégio Chaptal em Paris, e também em Lião, mas uma das primeiras realizações emblemáticas é o "livrete escolar de saúde" que teria sido introduzido no retorno às aulas de 1905 para os 6.000 alunos das escolas municipais da cidade de Nice (ROUX, 1905, p. 212). A caderneta está composta de duas partes distintas, a fim de respeitar o segredo profissional: um livretoe de saúde propriamente dito, destinado a permanecer em posse do aluno, e uma ficha de saúde arquivada num registro e conservada pelo médico-inspetor. Essa caderneta - pois o livrete também é assim chamado - possui informações gerais (sobre a admissão ou dispensa por causa de doença "duvidosa"), informaçôes individuais "que não podem de maneira alguma despertar a susceptibilidade dos pais", campos a preencher para indicar ausências e retornos em caso de doença, e, enfim, uma página dedicada a recomendaçóes de higiene escolar: importância da iluminação, da limpeza da sala de aula, admoestação para não cuspir nem levar à boca os lápis, a fim de não se exporem à tuberculose, convite à vacinação contra a varíola etc. Quanto à ficha sanitária, ela é descrita como mais completa, muito provavelmente porque ela é composta de elementos mais médicos e precisos, incluindo aí informaçóes de ordem intelectual.

Paralelamente, no campo da proteção da infância que está em pleno desenvolvimento, o Orfanato de Paris também adota em 1906 uma "caderneta escolar" com o subtítulo "Notas médico-pedagógicas" (L'ORPHELINAT, 
1907 , p. 552). Espera-se que nessa caderneta sejam registradas as doenças anteriores da criança e seja detectado o ponto fraco a monitorar na escola. A sua originalidade está em, ao mesmo tempo, aliar uma vertente médica, reflexo da saúde geral da criança e do seu desenvolvimento, mas também a sua inclinaçáo pedagógica, composta por folhas destinadas a anotaçóes, nas quais são indicados o comportamento, o trabalho, a atenção, a memória e o progresso do aluno. A articulação entre o médico e o pedagógico é uma necessidade; constata-se, “[...] para que se possa perceber se os defeitos no trabalho das crianças não se devem a um vício da sua saúde geral e para descobrir se, tratando dessa saúde geral, intervindo para melhorá-la, não melhoraria também a sua instrução e a sua educação" (L'ORPHELINAT, 1907, p. 522).

Ao longo dos debates, se esse tipo de caderneta é no seu conjunto pouco contestado, e se a questão é, sobretudo, a de melhorar sua difusão e sua destinação; ela é percebida, no entanto, por vezes como limitada no seu alcance. Com efeito, se ela diz respeito ao mesmo tempo à fisiologia do aluno e ao seu comportamento, a dimensão psicológica ainda está em grande parte ausente, por mais que se desenvolva dentro da escola uma ambiciosa psicologia da criança. A caderneta aparece como um desafio suplementar dessa psicologia da criança no processo científico de conhecimento dos estudantes, particularmente para Alfred Binet, que assumiu a direção do Laboratório de Psicologia Fisiológica da Sorbonne a partir de 1894 e trabalha em 1905 numa escola da Rua de Grange-aux-Belles em Paris com o Dr. Théodore Simon, com o qual ele acaba de realizar uma primeira versão da sua escala métrica da inteligência (OUVRIER-BONNAZ, 2011). Este pretendia, de fato, acrescentar à caderneta de saúde e às mensuraçóes dos estudantes reclamadas pelos médicos uma "caderneta psicológica", registrando dessa vez também as mensuraçóes do "valor intelectual das crianças e das suas diferentes aptidóes" (CHABOT, 1905, p. 384). A caderneta escolar, completada por uma caderneta psicológica, seria doravante uma ferramenta que permite contribuir para a classificação das crianças escolarizadas a fim de identificar os "anormais da escola", uma questão colocada na agenda política com força desde a constituição, em 1904, por uma comissão ministerial apelidada "Burguesa”, à qual cabe estudar a aplicaçáo da obrigação escolar às crianças anormais, e que desembocará na instituição de aulas e escolas de aperfeiçoamento em 1909 (VIAL; HUGON, 1998). 
A escola figura, então, como um lugar privilegiado para identificar as crianças anormais, e diversos países adotaram uma legislação que favorece uma educação especial. A nova psiquiatria da criança torna-se também uma ferramenta de classificação dentro desse período marcado pela obsessão pelas categorizações e pela seleção. Traçando uma via científica a serviço da identificação dos jovens delinquentes e de uma etiologia da delinquência juvenil; essa especialidade abre um caminho para delinear uma necessária clínica da criança delinquente e a individuação dos meios de investigação psiquiátricas a serviço das varas da infância, por exemplo, pela aplicação de "fichas médico-pedagógicas" (CHAZAL, 1907, p. 39). Disso é testemunho também o papel de Georges Heuyer no cruzamento entre anormalidade juvenil, delinquência e escola. Tendo passado pela medicina militar e pela neurologia, Heuyer orienta-se bastante cedo para a psiquiatria e para o estudo das patologias mentais da infância, como se vê na sua tese de medicina defendida em 1912 sob a orientação de Ernest Dupré, médico alienista no hospital Sainte-Anne e titular da cadeira de doenças mentais e do encéfalo, com quem ele realizou a última etapa da sua residência: Crianças anormais e delinquentes juvenis. Necessidade do exame psiquiátrico dos estudantes. Heuyer faz a ligação entre anormais da escola e delinquentes juvenis, ainda que considera importante a caderneta de saúde dos estudantes, acredita que ela está por demais orientada sobre os exames antropométrico e visceral, comparado com o limitado lugar deixado para o exame psicológico (HEUYER, 1914, p. 19).

A Primeira Guerra Mundial não pôs termo a esse projeto de saúde pública nascido na trilha deixada pela nova psicologia da infância, pela psiquiatria infantil e mais ainda pela higiene mental da infância. A caderneta médico-pedagógica, sobretudo vista no campo escolar, comporta uma finalidade profilática e torna-se, assim, uma ferramenta de inscrição da hereditariedade tanto quanto de identificação das deficiências, com uma finalidade às vezes abertamente eugenista, como reivindicam, por exemplo, certos meios políticos e filantrópicos para os quais uma caderneta médico-pedagógica é uma ferramenta indispensável de seleção e de tratamento das crianças anormais ${ }^{6}$. A própria caderneta de saúde torna-se

6 Ver também: “Le Convent du droit humain”. L'CFuvre, 20 set. 1926. 
um desafio para essas correntes, e Catherine Rollet ressalta as publicaçóes nesse sentido, desde o Livrete médico e sanitário (Caderneta de saúde individual e privada), publicado em 1923 por Camille Piétri, “[...] destinado a acompanhar, ao longo de toda a sua vida, o seu detentor, para anotar as fraquezas do seu organismo [...], para identificar as doenças ocultas e as deficiências", no qual são previstas a marcação das "deficiências ou fraquezas constitucionais", até o projeto de Louise Hervieu no final dos anos 1930 (ROLLET, 2007, p. 71).

\section{Uma caderneta para a criança vítima da guerra ou a arte de fazer do velho o novo?}

Ao apagar das luzes da Segunda Guerra Mundial, enquanto a caderneta de saúde se tornou obrigatória e o seu uso generalizado na França, retomando um modelo finalmente instituído em 1939 pelo ministro da Saúde Pública, Marc Rucart, a ideia de uma caderneta médico-pedagógica continua a abrir o seu caminho, dessa vez junto das crianças vítimas da guerra. $\mathrm{Na}$ leitura dos arquivos, desde os primeiros encontros dos membros fundadores dos SEGEP, a caderneta médico-pedagógica é uma hipótese forte. Ela é evocada sob o nome de "passaporte médico-pedagógico", a fim de ser mais facilmente compreendida enquanto ela se enraíza num contexto no qual as crianças estáo em perpétuo movimento numa Europa de cinzas e de ruínas, um mundo no qual os deslocamentos de crianças continuam sendo muito numerosos (ZAHRA, 2013). Enquanto novas vulnerabilidades em crianças são descritas e abordagens desvinculadas de uma leitura puramente biológica ou hereditária ganham importância, ainda assim ficamos impressionados com as referências deste projeto a iniciativas anteriores. Os primeiros comentadores darão, aliás, sua aprovação a esse trabalho, porque os especialistas dos SEPEG teriam considerado a experiência adquirida e principalmente as tentativas precedentes de criação de fichas médicas e pedagógicas ${ }^{7}$.

Os SEPEG reúnem médicos, psicólogos, magistrados, pedagogos e assistentes sociais da Suíça, antes de juntarem-se a esses os especialistas da

7 Mais informaçãoe em: Paris, archives Unesco: Conference of Allied Ministers of Education (Came) - Commission of Enquiry on Special Educational in the Liberated Countries, Special Educational Problems in the Liberated Countries, General Report, appendix 3, p. 4. 
infância de outros países. Esse projeto de "passaporte médico-pedagógico" origina-se de dois princípios estabelecidos por esses especialistas, que chegaram a um consenso. $\mathrm{O}$ primeiro é que todas as crianças teriam sido vítimas da guerra, certamente em diferentes intensidades. Por conseguinte, o segundo princípio, propóe encontrar novos modos de organizar o socorro a essas crianças, no sentido de uma racionalização, principalmente médica, da identificação e do tratamento, com atenção especial à psique:

[...] será mister proceder à identificação e a hospitalização de milhões de crianças e adolescentes, o que requererá a aplicação de métodos ad hoc. Dado que, nos países devastados pela guerra, todas as crianças terão sofrido, em maior ou menor medida, danos psíquicos e físicos, a ajuda psicológica às crianças normais confundir-se-á com a das crianças neuróticas, deficientes etc. Entretanto, por meios técnicos, será possível diferenciar as crianças apátridas deficientes constitutivas das crianças unicamente estigmatizadas pela guerra (choques psíquicos). (LAUSANNE, 1944, p. 1035-1062)

Este trabalho de normalização está a cargo de um "perito humanitário" que deve desenhar com preocupação o diagnóstico, avaliação do pedido de ajuda, elaboração de um projeto ad hoc e ajuste das competências profissionais (COLLOVALD, 2001). Nesse registro, a linguagem da reforma é aquela estabelecida pelos profissionais para a recomposição das práticas com relação às necessidades avaliadas pelos especialistas. Essa orientação é igualmente perceptível no recorte operado para definir as seçóes nas quais deve efetuar-se um trabalho mais especializado. Quando em fevereiro de 1945 o comitê de iniciativa dos SEPEG se lança na organização de uma grande conferência internacional que deveria acontecer em Zurique em setembro, cinco seçôes são definidas: ajuda ao alojamento provisório, à repatriação e às migraçóes; médica e médico-psicológica; pedagogia da infância deficiente; jurídica; cultura e lazeres.

A seção "médica e médico-psicológica" rapidamente se torna central. A sua presidência é confiada ao psiquiatra Lucien Bovet, então médico-chefe da Secretaria Médico-pedagógica de Vaud, em Lausana. Ele tem à época 37 anos e é uma figura ascendente da psiquiatria da criança, especialidade em pleno desenvolvimento na Europa. Após os seus estudos de medicina em Lausana, concluídos em Berna e na Bélgica, ele é nomeado assistente no asilo de alienados de Céry e torna-se subdiretor ao cabo de seis me- 
ses. Em 1938 ele é nomeado para a direção médica do "Bécail”, pavilhão-anexo para "crianças nervosas" no Hospício da Infância. Mais tarde ele participa da fundação da Secretaria Médico-pedagógica, inspirada nos Child Guidance Clinics, onde se conjugam prevalência do ambulatório, equipe médico-pedagógica com psiquiatra, psicólogo e assistente social e interesse pela psicanálise. Ligado à clínica, ele tem também um pé no mundo acadêmico, já que é desde 1942 privat-docent da Faculdade de Medicina da Universidade de Lausana. A seu lado, dois quadros da psiquiatria na Suíça germânica: Jakob Lutz, chefe da Policlínica de psiquiatria infantil e do centro de observação de Zurique, e Moritz Tramer, chefe dos estabelecimentos psiquiátricos de Soleure.

Nos trabalhos preparatórios, antes mesmo da conferência de Zurique, três grandes eixos de trabalho delineiam-se. Trata-se, num primeiro momento, da identificação e do diagnóstico a partir de uma investigação do conjunto da personalidade. Ela se refere primeiramente ao plano fisiológico, a fim de identificar a partir de exames antropométricos e neurológicos os "tipos constitutivos", a sífilis congênita, assim como as deficiências, mas também os diversos "pequenos sinais". A motricidade é igualmente um elemento avaliável, no qual são elencados ambidestria, distúrbios da linguagem, lexicais, gráficos, tiques, ou ainda enurese. Enfim, a personalidade da criança deve ser avaliada por testes simples e rápidos e, sobretudo, apoiando-se pouco sobre a linguagem, para mensurar ao mesmo tempo a sua educabilidade e o seu nível escolar, passando pelo seu caráter. $\mathrm{O}$ segundo momento corresponde à "notação esquemática", a saber, o "passaporte médico-pedagógico”. A ideia é pensar:

[...] uma fórmula ao mesmo tempo simples e completa, podendo ser aplicada por auxiliares sem formação especial aprofundada, podendo ser compreendida em todos os países, fornecendo, se possível em forma de gráfico, uma imagem geral da pessoa somato-psíquica da criança. Possibilidade de utilizar duplicatas dessa ficha com objetivos estatísticos, científicos etc. (LAUSANNE, 1944, p. 1035-1062).

A ferramenta pretende ser, pois, manejável e universal, simples de fabricar e usar e podendo ultrapassar as fronteiras. Enfim, num terceiro momento, a parte terapêutica da reflexão dos SEPEG é tanto somática (endocrinologia, vitaminas etc., mas também ginástica médica, climatoterapia etc.) quanto psíquica, ao mesmo tempo no plano das psicoterapias 
(psicoterapias psicagógicas, de inspiração analítica - Tienfentherapie) e no campo dos tratamentos médico-pedagógicos.

Nesse emaranhado, o “passaporte médico-pedagógico” reveste-se de uma importância tão forte que uma comissão ad hoc é formada durante a primeira conferência internacional dos SEPEG. Composta de suíços e estrangeiros, sobretudo francófonos, são todos psiquiatras ou psicólogos. Conquanto seja difícil conhecer os arcanos da designação dos membros, a sua composição mostra um equilíbrio e muito provavelmente abrange desafios dentro dos meios médico-pedagógicos. A escolha da presidência é, por exemplo, reveladora, já que ela recai sobre Geroges Heuyer, figura maior da psiquiatria infantil desde a Primeira Guerra Mundial na França, mas também internacionalmente (BOUSSION, 2016), que, desde muito tempo, defendeu a causa da implementação de uma caderneta médico-pedagógica para todos os estudantes e que contribuiu para a generalização do exame médico-psicológico a fim de identificar as crianças anormais.

Com a possível exceção de Oscar Forel, fundador e presidente dos SEPEG, cujo interesse pela infância é recente, todos os outros membros da comissão compartilham ligaçôes mais antigas que traçam uma continuidade com trabalhos anteriores no campo médico-psico-pedagógico. Assim, por exemplo, Henri Wallon ilustra muito bem essa orientaçáo, ocupando a cadeira de psicologia e educação da criança no Colégio da França e que acaba de publicar As origens do pensamento na criança; entáo, ocupa-se, em parte, com a reforma do ensino na França no quadro do que será chamado o Plano Langevin-Wallon. Há também toda uma rede originada no Instituto das Ciências da Educação de Genebra (Marguerite Loosli-Usteri, Henri Brantmay, André Rey e, num menor grau, Lucien Bovet), desenvolvendo os seus trabalhos no campo pedagógico. Essa orientação médico-pedagógica é também a da psiquiatra Jeanne Jadot-Decroly, que segue os passos do seu pai e dirige o Instituto de Educação Especial Decroly em Bruxelas. Enfim, outra influência perceptível é a do testing entre os psicólogos da comissão, seja Henri Wallon, Marguerite Loosli-Usteri, especialista do Rorschach que ela ajudou a fazer entrar em circulação antes da guerra, principalmente na França, André Rey, que se tornou uma referência da 
psicologia aplicada e dos testes, principalmente com vistas à orientação profissional, ou ainda o luxemburguês Nicolas Braunhausen, que produziu ensaios sobre alunos de uma escola profissional e estabeleceu uma ficha individual com elaboração de todo um perfil antropométrico e psicológico relacionado com especialidades profissionais nos quais os alunos tinham mais chances de ter sucesso (BRAUNSHAUSEN, 1919).

Muito rapidamente, o documento que eles são encarregados de produzir muda de nome; sob a pressão de Heuyer principalmente; de "passaporte médico-pedagógico" ele se torna "caderneta médico-pedagógica”. A razão invocada é a conotação demasiado policialesca da referência ao passaporte, visto que em 1945 a sua emissão ainda é um processo complicado em muitos países, e que o termo traria finalmente as crianças à sua condição de perpétuos deslocados. Resulta dos trabalhos um documento que, num certo sentido, é o produto da situação do pós-guerra. A parte "estado civil" pede respostas breves mas estabelecidas segundo os critérios do momento: origem, nacionalidade, religião, endereço atual, língua(s), etapas ou transferências com datas, que lembram as internaçóes e outros alojamentos em campos ou em casas de acolhimento, descrição física sumária. Ela contém, em seguida, toda uma parte somática, com exame físico geral (controle dos órgãos, mas também do sistema nervoso, do aparelho endócrino e do grupo sanguíneo). As duas páginas seguintes, dispostas uma do lado da outra, são dedicadas primeiramente aos antecedentes familiares, com detalhamentos sobre os antecedentes pessoais (traumatismos no nascimento, parto, primeiros desenvolvimentos etc.), uma breve pesquisa social, um resumo da escolaridade, um exame intelectual (diferentes testes), do caráter (temperamento e emotividade, adaptação familiar e escolar); enfim, uma visão sobre a orientação profissional (desejos da criança, aptidóes, testes). As duas últimas páginas impressas são reservadas, de um lado, a uma espécie de esquema de síntese, um "perfil evolutivo da criança” representado em forma de diagrama; de outro lado, espaços vazios reservados a fotos de identidade, de frente e de perfil, à orientação antropométrica, referindo tanto ao lado policial quanto ao lado humanitário do pós-guerra. Em seguida, páginas brancas estão inseridas na caderneta a fim de registrar cronologicamente o desenvolvimento da criança ao longo da tutela 
pedagógica, sem maiores indicações, muito provavelmente para respeitar o tempo e a escrita própria do domínio pedagógico.

Assim, esse documento, que se prevê seja confiado à criança, esforça-se em fazer a síntese de todas as informaçóes que podem ser reunidas sobre ela. Sobre esse ponto, faz aparecer uma multiplicidade de pontos de vista (médico e psiquiátrico, psicológico, social e pedagógico), que põem em cena o que se denomina então "equipe médico-pedagógica" (BOUSSION, 2020). Mas essa linguagem da reforma não conseguiria esconder as referências antigas constantes nessa caderneta - ainda que haja a tendência nos SEPEG de reconhecer na criança novas vulnerabilidades, como a possibilidade de ter sofrido um trauma consecutivo aos eventos de guerra -, seus distúrbios não estão necessariamente relacionados com a sua hereditariedade, nem com o seu meio. (BOUSSION, 2020). A escolha de confiar a realização do perfil evolutivo da criança a Henri Brantmay tem a ver principalmente com essa arte de fazer do velho o novo, porque ela diz respeito, sobretudo, à predominância de uma leitura biológica em detrimento da posição crescente tomada pela psicanálise na clínica infantil, na Suíça e em outros países europeus. Elaborado há vários anos a partir das observaçóes que ele realiza no Serviço de Observação Médico-Pedagógica das Escolas, assim como no atendimento às crianças nervosas do Instituto das Ciências da Educação em Genebra, o perfil de Brantmay liga-se à noção de ritmo da criança, buscando representar a dinâmica do seu desenvolvimento. Para tanto, ele elaborou uma tabela que busca representar as aptidóes (idade mental, memória, leitura, idade motora etc.) e os elementos estruturais (peso, altura), mas traduzidos em idade mediana, esses últimos sendo relacionados segundo coeficientes antropométricos elaborados nos anos 1930, tais quais os coeficientes de Bouchard e de Manouvrier, respectivamente para o índice de corpulência obtido dividindo a altura pelo peso e para o índice de crescimento medindo a diferença entre a altura do sujeito sentado e a do sujeito em pé. Uma linha reta é traçada à idade real da criança para cada um desses itens, tornando, a partir de entáo, visíveis os desvios à norma. Trata-se, assim, de uma das primeiras versóes do cronograma somato-psíquico tal qual publicado e explicitado em 1948 (BRANTMAY, 1948), pelo qual a criança é lida através de um quadro cifrado, no qual os 
sinais e as anomalias são resumidas e identificáveis num jogo de curvas, chegando a uma leitura bastante calculada e científica, assim como normativa, do desenvolvimento da criança (RUCHAT, 2003, p. 260).

\section{Sob o signo da observação}

Que difusão pôde ter a caderneta médico-pedagógica dos SEPEG? A sua finalização reflete ao mesmo momento na França a entrega gratuita da caderneta de saúde, tornada obrigatória por uma lei de 16 de dezembro de 1942 e confirmada por um decreto de 02 de novembro de 1945, numa perspectiva mais de monitoramento de saúde pública do que de controle, já que a sua implementação permanecia no estágio de recomendação (ROLLET, 2005). É nesse espírito da época que se faz circular a caderneta dos SEPEG, cuja capa azul tem muito a ver com aquela da caderneta de saúde francesa desse período. Encontram-se algumas pistas do seu envio a diferentes organizaçôes. Por exemplo, ela constitui um anexo do relatório elaborado pela Comissão de pesquisa sobre os problemas pedagógicos especiais dos países liberados, instalada pela Comissão dos ministros aliados da Educação (Came), que trabalhou de abril de 1945 a janeiro de 1946 sobre os efeitos da guerra sobre as crianças. Alguns exemplares também foram enviados à United Nations for Relief and Reconstruction Administration (Unrra). Todavia, esse documento complexo ainda náo teria sido posto em circulação até 1946, como observa o psiquiatra belga René Dellaert:

[...] os modelos não foram postos em circulação. O fato é que ele existe e poderá proporcionar serviços inestimáveis à finalidade para a qual ele foi destinado, mas também como meio de informação internacional, nos tempos vindouros, que permitirão, em larga escala, intercâmbios educativos de jovens entre diversos países. (DELLAERT, 1946, p. 70).

As ambiçóes são pois reduzidas, tanto que, segundo ele,

[...] nenhuma realização prática dessas grandes visões de conjunto pode ser esperada enquanto um organismo mundial, referendado por todos os governos, não regular e nivelar as múltiplas dissidências e dificuldades ligadas a uma colaboração tão estreita entre estrangeiros, num assunto tão íntimo quanto a educação das suas crianças afetadas. (DELLAERT, 1946, p. 70).

Apesar de que a caderneta pretender unificar práticas e tornar universal a identificação e o monitoramento das crianças da guerra, há mui- 
tas chances de que, tal como está, ela seja incapaz de racionalizar numa grande escala os monitoramentos médicos e pedagógicos. Antes, por sua concepçáo mesma, ela continua a aferrar as crianças num sistema de observação e avaliação. Ela se inscreve certamente numa dinâmica contemporânea do exame, na qual as crianças são submetidas a numerosos testes dentro das instituiçóes-modelo do período para a infância dita "inadaptada": os centros de observação. Acolhidos durante ao menos três meses nesses estabelecimentos na condiçáo de internados, meninos e meninas são submetidos a exames de todo tipo e ao longo de toda a sua estada, após a qual eles serão novamente encaminhados com vistas à sua reeducação ou entregues à sua família. Crianças e adolescentes são submetidos a um verdadeiro estudo comportamental individual, observados sozinhos e em grupo, desde o professor que organiza um "simulacro de escola" ao psiquiatra, passando pelo monitor de oficina, o educador encarregado das atividades ou ainda uma personagem reconhecida pela sua especialidade: o psicólogo. Todos estão encarregados de identificar eventuais distúrbios e deficiências, mas também de auferir as suas capacidades (GARDET, 2010). Abre-se, então, um novo período, no qual o teste e o monitoramento psicológico se generalizam. "Fala-se muito hoje em dia do exame psicológico ou psicotécnico das crianças colocadas em observação ou recebendo atendimento", segundo Mireille Monod (1946 apud RAUSCH DE TRAUBENBERG, 1978), conselheira de orientação profissional encarregada do serviço psicológico na Fundação Rollet, instituição responsável pelas crianças nas varas da infância.

A ideia de envolver as crianças no seu próprio acompanhamento psicológico não é abandonada. Entretanto, para Mireille Monod, nesse momento haveria uma falta de conexão entre estabelecimentos, entre profissionais, assim como o uso, às vezes abusivo, dos testes com uma mesma criança, que é submetida aos mesmos testes várias e várias vezes. É também na condição de especialista desse teste que ela se coloca e constata que, nesse contexto, esse teste não mais teria valor objetivo, o exame psicológico transformando-se em "formalidade absurda pela qual se deve passar", e esses "exames repetidos soam às crianças como um insulto (e são, de fato!)", o que acaba por fechá-los a qualquer comunicação. Daí a necessidade e a urgência, segundo ela, de estabelecer um "passaporte psicológico” ou dos- 
siê psicológico sucinto que seguiriam a criança, sob a égide do ministério da Saúde ou o da Educação nacional. Ela o imagina contendo a data, o lugar do último exame psicológico, assim como o nome dos testes aplicados, permitindo não realizar novamente o mesmo teste e ao mesmo tempo fazer referir o último serviço psicológico no qual foi examinada a criança. Nesse sentido, essa caderneta confiada à criança é uma ferramenta de racionalização e de ligação, mas também de higiene psicológica: "Parece que uma criança poderia saber sem inconveniente, se lhe der vontade de ler o passaporte psicológico, que ela fez o Binet-Simon, assim como poderia saber se foi vacinada contra a difteria." Ela vê aí, enfim, a ocasião de verificar no plano científico, em grande medida, os valores preditivos dos testes, com base na psicotécnica e na orientação profissional.

Pois é exatamente essa dimensão de orientação que prevalece doravante na ideia geral do "dossiê", ele seja ou não confiado à criança e à sua família. Já no entreguerras, os escritos perseguem essa ideia da classificação e da adaptação dos dados psicológicos e das aptidóes intelectuais, mas cada vez mais com relação à inserção no mercado de trabalho. Sob a influência de uma psicologia científica e da nova educação, há, então, toda uma atividade de observação encarregada de detectar as aptidóes da criança não somente no nível escolar, mas também no nível da orientação profissional (MARTIN, 2015). Surge a ideia de "uma caderneta médica na qual seriam compiladas fichas somáticas, neurológicas e psicológicas que seguiriam cada indivíduo e cujas observaçóes forneceriam para cada adolescente de 16 anos as bases para a sua orientaçáo profissional, em suma, todo um perfil psicológico" (REVAULT D’ALLONNES, 1925, p. 368).

Desde os anos 1930, a psicologia progride em diversos setores na França (LE BIANIC, 2013). Ela ocupa um lugar crescente, por exemplo, dentro do campo da infância sob tutela judicial, mas também nos interstícios oferecidos pelo desenvolvimento do dito setor da "infância inadaptada": centros de observação, centros médico-pedagógicos ou centros médico-psicopedagógicos. Tanto é que cada vez mais oportunidades se oferecem aos psicólogos, formados em número cada vez maior com a instauração da licença em Psicologia em 1947. Impóe-se a figura do psicólogo escolar, que existe antes da guerra em número muito reduzido, principalmente na 
sequência dos trabalhos de reforma do ensino sob a influência de Henri Wallon. Esse novo especialista encontra-se encarregado da identificação da fadiga escolar, da má adaptação escolar, passando pelos métodos pedagógicos. Esses postos são ocupados por professores que obtiveram os certificados do Instituto de Psicologia e, apesar dos efetivos permanecerem sendo poucos até o final dos anos 1950, eles encarnam, aos lado do orientador, o novo lugar da Psicologia junto às crianças. No cerne do projeto de Wallon, isso se acompanha também na sua ideia de observação contínua da criança e do seu desenvolvimento, da necessidade de uma caderneta psicológica para cada criança na escola, a exemplo da caderneta de saúde que ela já possui, estabelecida pelo psicólogo escolar:

Eu gostaria que, nas escolas, cada criança tivesse a sua caderneta psicológica, assim como ela deve ter a sua caderneta de saúde. Eu gostaria que, nessa caderneta psicológica, houvesse uma página para cada idade e que, para cada idade, houvesse um perfil psicológico. [...] Eu creio que a comparação desses perfis psicológicos de idade em idade para a mesma criança mostraria para o orientador uma curva de crescimento ou uma série de desenvolvimentos infinitamente mais sugestiva que qualquer dos resultados que ele poderia obter vindo à escola, quando as suas ocupações Ihe permitissem, para fazer alguns testes coletivos, ou mesmo para fazer alguns exames individuais. (WALLON, 2015, p. 120).

Entretanto, parece que o esforço tenha sido levado nos anos 1950-1960 para o dossiê individual, perdendo de vista a própria ideia de fazer circular um documento entre os pais e os profissionais, como poderia tê-lo sido uma "caderneta psicológica” ou “caderneta médico-pedagógica”. Médicos e psicólogos concentram-se sobre a sua realização, a sua composição, e fazem a lista das rubricas a comentar, incluindo a maneira de obter informaçóes junto dos pais. Os dossiês tornam-se cada vez mais volumosos e parecem ter como objetivo a sua própria construção, representando a força da instituição. A escola não está isenta desse movimento, longe disso, no momento no qual se constitui o dossiê escolar sob a influência de Roger Gal:

Empenhar-nos-íamos, por exemplo, em examinar as crianças quanto às suas capacidades de observação, de imaginação, de emotividade etc., a inventar cada um de nós, no seu domínio, os exercícios, provas e testes capazes de informar-nos sobre esses pontos. Aproximar-nos-íamos em seguida dos resultados e registraríamos nos dossiês escolares individuais as observações mais seguras, ainda que com as suas contradições às vezes esclarecedoras. Esses dossiês acompanhariam os alunos do começo ao fim dos seus estudos, agrupando, assim, além dos resultados escolares, todas as observações sobre a vida física, afetiva, intelectual, social e moral do indivíduo. (GAL, [1948] 1955, p. 48). 
Nada é dito em contrapartida sobre a possibilidade de um documento que poderia ser lido pela criança ou pelo próprio adolescente, a instituição afirma seu poder sobre a criança, apartando-o dos escritos fabricados sobre ela, passando "[...] de uma noção de vida privada secreta em si para uma noção de vida privada secreta para si” (LAMARCHE-VADEL, 1980, p. 45). Na esteira de uma nova "política dos usos" (POTTE-BONNEVILLE, 2004) a partir do final dos anos 1970, o olhar parece inverter-se. As instituiçóes, consideradas todas como "totais" ou "totalitárias", são percebidas essencialmente como agentes de repressão, de controle e de policiamento das populaçóes e dos comportamentos, principalmente porque aí se aprofundaria cada vez mais "a aliança segredo-poder" (LAMARCHE-VADEL, 1980, p. 45). O dossiê individual dos menores ocupa, nesse contexto e no campo da infância sob tutela judicial, "um lugar de escolha": "de um lado, na medida em que ela simbolizaria os procedimentos do segredo organizados pela justiça; de outro lado, pelo que conteria de práticas inquisitoriais, classificatórias e interpretativas operadas em torno da criança" (DONZELOT, 1977, p. 109). Ademais, a própria abordagem individual é contestada, assim como o princípio da observação quando ele é subentendido pelos desejos de classificação e identificação ${ }^{8}$, que encerraria a criança na condição de "inadaptada" e polarizaria o aluno, a criança ou o adolescente sobre as suas próprias dificuldades. À psicologia individual, portanto, seria preferivel, no minimo, uma abordagem da psicologia social ou mesmo da sociologia, que seria, portanto, menos focada no caráter preditivo ou normativo.

\section{Considerações finais}

A mudança de horizonte não conseguiria captar o conjunto das experiências das cadernetas médico-pedagógicas e médico-psicológicas na França do século XX, menos ainda na sua dimensão internacional. No entanto, ela permite a pequenos passos identificar diferentes períodos nos quais se refletem a pertinência, os usos e a ambição de tal objeto. Claramente ancorada numa perspectiva higienista do início do século, ela adquire também mui rapidamente uma dimensão profilática no sentido de que ela deveria permi-

8 Em 1979, foi publicado sobre esse tema o dossiê "L'observation des enfants et le fichage": Education et développement, n. 136, out. 1979. 
tir identificar o mais rápido possível as fraquezas e anormalidades da criança. Nesse sentido, a escola vai desempenhar um papel maior nas discussóes, pois ela aparece ao mesmo tempo como lugar de socialização por excelência da criança e como o lugar da sua orientação. Contemporâneo com o surgimento da psicologia e da psiquiatria infantil, a caderneta tem sido, portanto, a aposta no desenvolvimento de perfis psicológicos individuais. Mas é talvez no final da guerra que o modelo de caderneta médico-pedagógica realiza melhor a junção entre as diferentes abordagens, fruto de circulações transnacionais acentuadas e de uma situação na qual mais do que nunca a criança se torna objeto de experimentos, ainda mais por ela representar uma forma de clientela cativa, sem lar nem pátria, aparecendo quase nua, em estado bruto.

Após um apogeu no rastro de uma psicologia que se pretende ainda mais científica, e depois contestada abertamente pelos próprios profissionais nos anos 1970-1980, essas experiências de escrita náo param, no entanto, de levantar questóes. No fundo, elas revelam um desejo poderoso e constante de exame e de observação da criança, que se encontra também na realização dos dossiês individuais, bem como uma tendência regular para um desejo preditivo cada vez mais precoce de transtornos em crianças. Elas são o reflexo de uma difusão dos saberes e práticas psicológicas que rodeiam a criança, até instituir uma leitura psicológica de todos os comportamentos infantis e revelar, ao final, todo um "poder de escrita" (FOUCAULT, 1975, p. 222). Mas, nesta fase, seria importante poder medir as distâncias entre as prescriçôes que dizem respeito à realização de tais cadernetas quando elas foram implementadas e as práticas reais dos profissionais e também dos usuários, inclusive nas práticas mais contemporâneas de empowerment em matéria de acompanhamento psicológico.

\section{Referências}

L'ORPHELINAT de la Seine. Rapport sur l'activité en 1906. La Revue philanthropique, v. XXI, p. 522, 1907.

ABOUT, I. Les fondations d'un système national d'identification policière en France (1893-1914). Anthropométrie, signalements et fichiers. Genèses, v. 54, n. 1, p. 28-52, 2004.

BOUSSION, S.; GARDET, M. Entre ombre et lumière: les dossiers de mineurs en justice au regard de la conservation, de la recherche et des pratiques professionnelles. In: ARCHIVES DE FRANCE. La protection de l'enfance. Écrits protégés, écrits ignorés. Paris: La Documentation française, 2010. p. 119-129. 
BOUSSION, S. Pour la Paix du monde: Sauvons les enfants! Les Semaines internationales d'étude pour l'enfance victime de la guerre 1945-1951. In: DENÉCHÈRE, Y., NIGET, D. (dir.). Droits des enfants au XX' siècle. Rennes: Pur, 2013. p. 63-71.

BOUSSION, S. Le premier congrès international de Psychiatrie infantile (Paris, 1937), ou le baptême d'une spécialité ambitieuse. Revue d'histoire de l'enfance "Irrégulière", n. 18, 57-80, 2016.

BOUSSION, S. Le tour d'Europe médico-pédagogique des Sepeg. Carnet de recherche Hypothèses L'internationale des républiques d'enfants 1939-1955. 06 jun. 2020. Disponível em: https:// repenf.hypotheses.org/5837\#more-5837. Acesso em: 3 agosto 2020.

BOUSSION, S. Hérédité vs traumatisme. Psychiatres et enfants victimes de la guerre 1945-1950. Journal français de psychiatrie, [s. p.], set. 2020 (no prelo).

BRANTMAY, H. Le chronogramme somato-psychique. Sauvegarde de l'enfance, p. 12-21, mar./ abr. 1948 .

BRAUNSHAUSEN, N. Psychologische Personalbogen als Hilfsmittel der Pädagogik und der Berufsberatung (Fiche psychologique comme auxiliaire de la pédagogie et de l'orientation professionnelle). Leipzig: Barth, 1919.

CHABOT, C. Revue de pédagogie. L’Année psychologique, v. 12, p. 384, p. 1905.

CHAZAL, E. Les anormaux psychiques. Contribution à l'étude de l'enfance anormale. ParisLyon: Ed. Maloine, 1907.

COLlOVAlD, A. De la défense des pauvres nécessiteux à l'humanitaire-expert. Reconversion et métamorphoses d'une cause politique. Politix, n. 56, p. 135, 2001.

CONGRÈS INTERNATIONAL D'HYGIÈNE SCOLAIRE. 3e Congrès international d'hygiène scolaire, Paris: Ed. A. Maloine, 2-7 ago. 1910.

DELLAERT, R. Les travaux de la section médico-psychologique des SEPEG. Le Service social, n. 3, p. 66-72, maio/jun. 1946.

DINET, R. Le dossier sanitaire de l'écolier, base nécessaire de la pédagogie expérimentale et du perfectionnement individuel. Deuxième congrès d'hygiène scolaire de pédagogie physiologique (11-13 juin 1905). Paris: Masson, 1904. p. 275.

DONZELOT, J. La police des familles. Paris: Ed. de Minuit, 1977.

DUFESTEL, L. Médecin-inspecteur. Buisson F. Nouveau Dictionnaire de pédagogie et d'instruction primaire. Paris: Hachette, 1911.

FOUCAULT, M. Surveiller et punir. Paris: Gallimard, 1975.

GAL, R. [1948]. L'orientation scolaire. Paris: Puf, 1955.

GARDET, M. De la prévention au dépistage ou l'affirmation des médecins scolaires (1879-1939).

Informations sociales, v. 161, n. 5, p. 14-21, 2010a. 
GARDET, M. Les dossiers de jeunes délinquants du centre d'observation de Savigny-sur-Orge. Un corpus inédit au défi de l'histoire. In: BANTIGNY, L.; VIMONT J-C. (dir.). Sous l'œil de l'expert. Les dossiers judiciaires de personnalité. Rouen: Presses des universités de Rouen et du Havre, 2010b. p. 133-144.

HEUYER, G. Enfants anormaux et délinquants juvéniles. Nécessité de l'examen psychiatrique des écoliers. Paris: éd. Steinheil, 1914. p. 19.

LAMARCHE-VADEL, G. Une justice en trompe l'œil. Le secret du dossier des mineurs. Recherches, n. 44, [s. p.], out. 1980.

LAURO, A. Écrire l'histoire des futurs dans le passé. Retour sur une conférence de Patrick Boucheron à l'ULB. 16 fev. 2017. Disponível em: https://amandinelauro.wordpress.com/. Acesso em: 10 set. 2020.

LAUSANNE, A. C. V. Fonds Oscar Forel. Manifeste des SEPEG, p. 1035-1062, nov. 1944.

LE BIANIC, T. Une profession balkanisée: les psychologues face à l'État en France (1945-1985). Politix, v. 2, n. 2, p. 175-207, 2013.

LETULLE, M. Le carnet individuel de santé. Premier congrès d'hygiène scolaire de pédagogie physiologique (1 $1^{\mathrm{er}}-2$ novembre 1903). Paris: Masson, 1904. p. 219-220.

L'ORPHELINAT de la Seine. Rapport sur l'activité en 1906. La Revue philanthropique, v. XXI, p. 522, 1907.

MARINOPOULOS, S. Mon carnet de santé psy. Paris: éd. Les liens qui libèrent, 2012.

MARTIN, J. L'orientation professionnelle et l'école dans l'entre-deux-guerres. Un exemple d'application de la psychologie. Les Sciences de l'éducation - Pour l'Ėre nouvelle, v. 48, n. 2, p. 45-68, 2015.

NIGET, D. Expertise médico-pédagogique et délinquance juvénile en Belgique au XXe siècle. Histoire@Politique, v. 14, n. 2, p. 38-54, 2011.

NOIRIEL, G. Réfugiés et sans-papiers. La République face au droit d'asile $\mathrm{XIX}^{\mathrm{e}}-\mathrm{XX}^{\mathrm{e}}$ siècle. Paris: Hachette, 1991.

OUVRIER-BONNAZ, R. Le laboratoire de pédagogie expérimentale de la Grange-aux-Belles. Recherches \& éducations, n. 5, p. 131-147, 2011.

POTTE-BONNEVILLE, M. Politique des usages. Vacarme, n. 29, supl. Michel Foucault 19842004, p. 66-73, 2004.

RAUSCH DE TRAUBENBERG, N. Hommage à Mireille Monod (1919-1976). Bulletin de la Société française du Rorschach et des méthodes projectives, n. 31, p. 115-118, 1978.

REVAUlT D’ALlONNES, G. Analyses et comptes rendus. André Collin, A. Les enfants nerveux. Diagnostic, pronostic, aptitudes. Paris: J.B. Ballière, 1925. Journal de psychologie normale et pathologique, 1925. p. 368. 
ROLLET, C. Pour une histoire du carnet de santé: une affaire publique ou privée ? Revue des affaires sociales, n. 3, p. 129-156, 2005.

ROLLET, C. Les carnets de santé des enfants. Paris: La Dispute, 2007.

ROUX, J-C. Le livret scolaire de santé. L'Enfant, 20 nov. 1905.

ROUX, J-C. Albert Mathieu, médecin de l'hôpital Saint-Antoine (1855-1917). La Presse médicale, Paris, n. 40, p. 417-418, 19 jul. 1917.

RUCHAT, M. Raisons disciplinaires, écritures cliniques et figures de l'enfant dans l'histoire de l'éducation spéciale 1867-1948. Studien und Quellen, n. 29, p. 243-264, 2003.

TSCHIRHART, A. Rôle et évolution de l'hygiène scolaire dans l'enseignement secondaire de 1800 à 1910. Carrefours de l'éducation, v. 26, n. 2, p. 201-213, 2008.

VIAL, M.; HUGON, M-A. La Commission Bourgeois (1904-1905). Documents pour l'histoire de l'éducation spécialisée. Paris: Éditions CTNERHI, 1998.

WALLON, H. Les principes de l'orientation à l'école et dans la profession, conférence du $1^{\text {er }}$ mars 1945, Union française universitaire. In: WALLON, H. CEuvres 4 1938-1950. Paris: L'Harmattan, 2015. p. 112-125.

ZAHRA, T. Les enfants perdus. Revue d'histoire de l'enfance “irrégulière”, n. 15, p. 23-74, 2013.

Recebido: 30/06/2020

Aceito: 20/07/2020 


\section{Medical-psycho-pedagogical writings on childhood: projects of individual reports cards in the 20th century}

\section{Abstract}

This article focuses on the projects of individual medical-pedagogical notebooks for children and their evolution. In the course of the twentieth century, numerous attempts were made to introduce a health record that would also take account of psychological and pedagogical data. They were initially aimed at school hygiene, but they were also deployed in the field of prophylaxis, in order to detect "abnormal" children, and later in the field of vocational guidance. The Second World War also produced a different approach, in terms of rationalizing the child's health and psychological writings, seeking to take into account the events and what they may have caused in the child, without abandoning the old categories, linked to the biological. No doubt the novelties are to be found more in what we intend to entrust the medical and educational notebook to the children, but this parenthesis will soon be closed and finally fade away in the face of criticism of what is then considered to be social control.

Keywords: History. Medical-pedagogical. Psychology. Child psychiatry. Health record. 